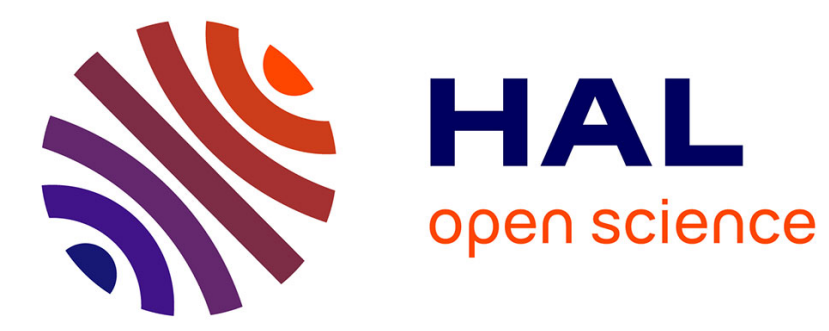

\title{
Maintenance scheduling in the electricity industry: a literature review
}

\author{
Aurélien Froger, Michel Gendreau, Jorge E. Mendoza, Eric Pinson, \\ Louis-Martin Rousseau
}

\section{To cite this version:}

Aurélien Froger, Michel Gendreau, Jorge E. Mendoza, Eric Pinson, Louis-Martin Rousseau. Maintenance scheduling in the electricity industry: a literature review. European Journal of Operational Research, 2016, 251 (3), pp.695-706. 10.1016/j.ejor.2015.08.045 . hal-01188261

\section{HAL Id: hal-01188261 \\ https://hal.science/hal-01188261}

Submitted on 26 Nov 2020

HAL is a multi-disciplinary open access archive for the deposit and dissemination of scientific research documents, whether they are published or not. The documents may come from teaching and research institutions in France or abroad, or from public or private research centers.
L'archive ouverte pluridisciplinaire HAL, est destinée au dépôt et à la diffusion de documents scientifiques de niveau recherche, publiés ou non, émanant des établissements d'enseignement et de recherche français ou étrangers, des laboratoires publics ou privés. 


\title{
Maintenance scheduling in the electricity industry: a literature review
}

\author{
Aurélien Froger ${ }^{1} \quad$ Michel Gendreau $^{2} \quad$ Jorge E. Mendoza $^{3} \quad$ Eric Pinson $^{1}$ \\ Louis-Martin Rousseau ${ }^{3}$
}

${ }^{1}$ LUNAM Université, Université Catholique de l'Ouest, LARIS EA7315, Angers, France

${ }^{2}$ Centre Interuniversitaire de Recherche sur les Reseaux d'Entreprise, la Logistique et le Transport (CIRRELT), Montréal, Canada Ecole Polytechnique de Montréal, Département de Mathématiques et de Génie Industriel, Montréal, Canada

${ }^{3}$ Université François-Rabelais de Tours, CNRS, LI EA 6300, OC ERL CNRS 6305, Tours, France

\begin{abstract}
The reliability of the power plants and transmission lines in the electricity industry is crucial for meeting demand. Consequently, timely maintenance plays a major role reducing breakdowns and avoiding expensive production shutdowns. By now, the literature contains a sound body of work focused on improving decision making in generation unit and transmission line maintenance scheduling. The purpose of this paper is to review that literature. We update previous surveys and provide a more global view of the problem: we study both regulated and deregulated power systems and explore some important features such as network considerations, fuel management, and data uncertainty.
\end{abstract}

This is a post-peer-review, pre-copyedit version of an article published in European Journal of Operational Research. The final authenticated version is available online at: https://doi.org/10.1016/j.ejor.2015.08.045

Citation for published version:

Froger A., Gendreau M., Mendoza J.E., Pinson E., and Rousseau L-M. (2016). Maintenance scheduling in the electricity industry: A literature review. European Journal of Operational Research, 251(3):695-706, doi:10.1016/j.ejor.2015.08.045.

(C)2015. This manuscript version is made available under the CC-BY-NC-ND 4.0 license

(http://creativecommons.org/licenses/by-nc-nd/4.0/) 


\section{Introduction}

The production of movement, heat, or light needs a common input: energy. Energy can be produced from fuel (e.g., oil, gasoline, uranium, gas, coal, wood) or natural forces (e.g., wind, water). The consumption of energy is growing with the development of countries and the increasing world population, and the production must meet this demand. Therefore, the reliability of power plants, and wind and solar farms is extremely important. In this context, equipment maintenance management is a major economic issue. Just to cite few examples, equipment maintenance management in electric power systems is concerned with decisions such as: when to stop a generation unit for maintenance, when to re-start it again, and how much resources (e.g., technicians) are to be assigned to the maintenance of a given unit during a given period. These decisions are taken under complex environments and constraints such as resource availability, demand satisfaction, and reliability thresholds.

One of the most successful contributions of operations research to improve decision making in equipment maintenance management is the application of optimization techniques to solve maintenance planning and scheduling problems. In the particular case of electric power systems, these problems range from simple technician-equipment assignments to complex problems considering interactions between different stakeholders and uncertainty in the problem parameters. In this paper, we build on the work of Yamayee (1982); Kralj and Petrović (1988); Dahal (2004); Khalid and Ioannis (2012) to update the state-of-the-art and provide a global overview of the current stream of research in the field. To make the document easier to read, the various acronyms used in this paper are summarized in Table 1.

Table 1: List of key terms and their acronyms

\begin{tabular}{ll}
\hline Acronym & Term \\
\hline GENCO & generation company \\
TRANSCO & transportation company \\
DISCO & distribution company \\
RETAILCO & retail company \\
ISO & independent system operator \\
GMS & generator maintenance scheduling \\
TMS & transportation maintenance scheduling \\
\hline
\end{tabular}

The paper is organized as follows. Section 1 presents a brief description of the energy industry, Section 2 reviews maintenance scheduling problems rising in regulated and deregulated environments, Section 3 discusses existing solution methods for these problems, and Section 4 concludes the paper and outlines research perspectives.

\section{The energy industry}

The energy industry carries out three activities: production, transmission, and distribution. Traditionally the industry is organized in a centralized, vertically integrated way (see Figure 1): a single company has a monopoly of the entire system in its area of operation. However, the government regulates the situation directly or indirectly: the entity must not take advantage of the end consumer. Therefore, the term regulated monopoly utilities is also used. With the deregulation of the electricity industry from the end of the 1990s, competition has been replacing monopolies in most places. 


\subsection{Deregulation of the power industry}

The deregulation (or liberalization) of the power industry has opened up the electricity market to competition. Several companies can now produce or distribute energy; it is, however, more difficult to introduce competition for the transmission management. Energy prices are no longer regulated by the government (hence the terms deregulation and liberalization) but are subject to market interactions. Regulations remain (sometimes the term restricted power system is used) but monopolies are no longer acceptable. Given the success of this system in the aeronautics, gas, and telephone industries, this reform is promoted as a benefit for the sector. It is intended to favor innovation, to lower prices, and to lead to better service. This new system introduces challenges such as the organization of the electricity market, the price-setting mechanism, and the coordination of the various actors.

Indeed, the introduction of market players leads to the emergence of new actors or redefines the role or activities of existing actors. An independent system operator (ISO) is responsible for the reliability and security of the system. It dispatches all or part of the energy transactions and can decrease loads on the network to avoid congestion. The ISO is the leading entity in a power market, and it must be fair. It manages the interactions between three key entities: the generating companies (GENCOs), transmission companies (TRANSCOs), and distribution companies (DISCOs). When a single TRANSCO owns the entire transmission network, the ISO operates the transmission lines. The TRANSCO is then paid for the use of its lines and the maintenance of its network (Shahidehpour et al., 2002). Retail energy service companies (RETAILCOs) act as intermediaries between GENCOs and consumers by buying energy from the former to sell to the latter. Other actors exist but their roles are relatively minor.

Energy transactions of different natures can take place in this new market structure. In a power exchange model, GENCOs and RETAILCOs negotiate bilateral contracts defining prices and quantities independently of the ISO. However, the availability of the transmission lines must be checked with the system operator to maintain security. This decentralized approach is opposed to the centralized approach (pool-based model) where market participants share extensive information (e.g., energy offer, start-up costs, generation costs, ramp-rate for each generator) with the ISO, which is responsible for ensuring the social and economic welfare of the market while keeping the system safe. Two kinds of bids are submitted to the ISO: producers' bids consist of energy blocks and their selling prices, and buyers' bids consist of energy blocks and their buying prices. The power price is determined by the balance between supply and demand using a market clearing process. Several markets such as day-ahead, intra-day, real-time or a combination can be encountered. Although they are different, both pool-based and power exchange models can coexist. Moreover, a transmission market deals with the purchase and sale of transmission rights. For a more detailed explanation of all these specificities, the reader is referred to Shahidehpour et al. (2002). Figure 2 summarizes the various interactions between the actors. It is however difficult to define a typical organization because several structures are possible.

Liberalization modifies and sometimes complicates power industry issues. GENCOs, TRANSCOs, and DISCOS mainly serve their own interests, which may call into question the stability of energy production and/or energy distribution. Regulations are therefore required.

After this brief presentation of the electricity industry, we discuss, in the next section, optimization problems in maintenance scheduling of generation units and transmission lines rising in both regulated and deregulated power systems. We focus on network constraints, on data uncertainty, and on fuel consumption and supply management. To provide a global overview, Table.2 classifies the references according to the problem they solve, the power system they target and the features they deal with. 


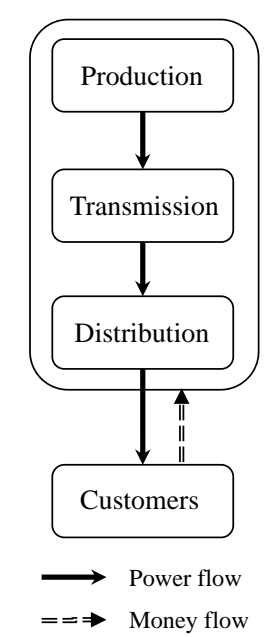

Figure 1: Interactions in a vertically regulated utility

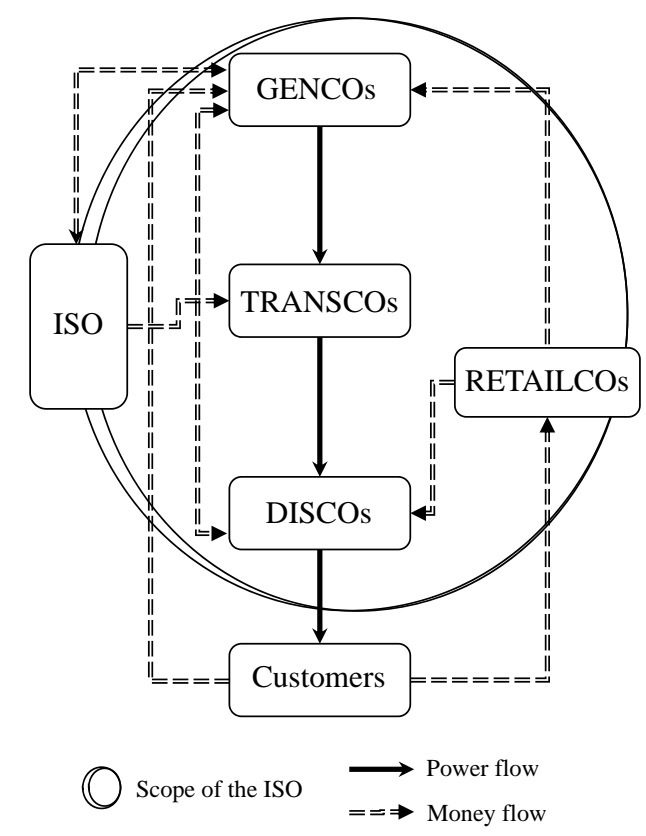

Figure 2: Interactions between market players under deregulation

\section{Maintenance in the electricity industry}

Maintenance represents the actions required to ensure that a product provides reliable service. Maintenance can be split into two categories: corrective and preventive. Corrective maintenance is performed after a breakdown. Preventive maintenance is performed at predetermined intervals or according to prescribed criteria and intended to reduce the probability of failure. Maintenance in the electricity industry concerns generation units and transmission lines; the horizon can be long-term or short-term. In this paper, we do not discuss failure prediction or maintenance policies that will manage the risks of equipment failure in the most effective way. We refer the reader to Doyle (2004); Yssaad et al. (2014) for literature dealing with those problems. We consider defining time intervals for preventive maintenance for the equipment, given financial and reliability considerations.

\subsection{Maintenance scheduling of generating units}

The maintenance scheduling of generation units has been widely studied. On its basic version, the maintenance scheduling problem consists in defining when to stop the generating units for preventive maintenance in order to maintain the system reliability and to reduce the general operational costs. We refer to it as the generator maintenance scheduling (GMS) problem. Additional constraints include, but are not limited to:

- maintenance tasks: maintenance window (possible time for maintenance), sequence, incompatibility, spacing, and overlapping of tasks.

- generating units: highest/lowest production levels, ramp-rate ${ }^{1}$.

- manpower: availability for each period, requirements by maintenance tasks.

- resources: availability for each period, requirements, consumption by maintenance tasks.

- network: transmission-line capacity (see Section 2.2), voltage.

\footnotetext{
${ }^{1}$ Output gap limitation between two successive periods for a generating unit
} 
- demand: fully satisfied or not, meeting of demand, energy-not-served (ENS) threshold.

- reliability: minimum reserve required by period, risk levels, ENS.

This optimization problem is generally NP-hard and may be nonlinear and nonconvex. Moreover, the power production is strongly impacted by maintenance decisions. To include load constraints, especially demand satisfaction, in the GMS problem, it can be necessary to simultaneously decide the production levels of the generating units and the maintenance scheduling. The solutions obtained can then be used as guidelines for unit commitment $(U C)$ with a short time horizon. UC aims to schedule generating units level to meet forecasted load and reserve requirements.

In the next two sections we discuss the GMS problem in regulated and deregulated power systems.

\subsubsection{Regulated power systems}

Monopolies still operate in some regions. In a vertically integrated utility, the maintenance is scheduled in a centralized way, and all the information is available (costs, network, etc.). The various studies can be classified according to the nature of the considered objective function:

\section{- Reliability-based}

References : (Baskar et al., 2003; Canto and Rubio-Romero, 2013; Chen and Toyoda, 1991; Dahal and McDonald, 1997; Dahal et al., 1999; Dahal and Chakpitak, 2007; Ekpenyong et al., 2012; El-Amin et al., 2000; Fetanat and Shafipour, 2011; Foong et al., 2007; Mohanta et al., 2004, 2007; Reihani et al., 2012; Schlünz and van Vuuren, 2013; Suresh and Kumarappan, 2013; Volkanovski and Mavko, 2008; Wang and Handschin, 2000; Yare and Venayagamoorthy, 2010).

For reliability, the main optimization criterion is the leveling of the net reserves along the planning horizon. For a given period $t$, the net reserves correspond to the maximal power that can be produced by the available generating units not in maintenance at $t$ minus the estimated demand during $t$. The most common approach is to minimize the sum of squares of the net reserves by period (Dahal and McDonald, 1997; Dahal et al., 1999; Dahal and Chakpitak, 2007; Ekpenyong et al., 2012; Foong et al., 2007; Mohanta et al., 2004, 2007; Reihani et al., 2012; Schlünz and van Vuuren, 2013; Yare and Venayagamoorthy, 2010). In contrast, Chen and Toyoda (1991) maximized the reserve margin when isolated power systems are tackled, whereas they leveled the reserve margin for each area when a multi-area system is considered. Suresh and Kumarappan (2013) and Wang and Handschin (2000) leveled the reserve margin by minimizing an objective function based on the deviation between a reserve rate and its average (i.e. the average reserve rate over the planning horizon). Suresh and Kumarappan (2013) defined the reserve rate as the ratio of the net reserve to the sum of the generation capacity plus the predicted maximum load while Wang and Handschin (2000) defined the reserve rate as as the ratio of the difference between the sum of the generation capacity minus the maximum predicted load to the maximum predicted load. El-Amin et al. (2000) considered the deviation between the reserve by period and the average reserve along the horizon. Baskar et al. (2003) considered the square of this deviation and study the impact of a crew constraint (manpower availability at each period) on the results. Canto and Rubio-Romero (2013) maximized the sum by period of the ratio of the net power reserves to the gross power reserves. They introduced geographical, seasonal, and coordination constraints for a problem with wind farm turbines and thermal and hydroelectric power plants. Volkanovski and Mavko (2008) minimized the annual value of the loss of load expectation (LOLE) ${ }^{2}$ taking into account the forecasted outage rate of the generating units. Finally,Fetanat and Shafipour (2011) defined an objective function such as the generating units have to be maintained as promptly as possible to reduce the expenses related to damaged machines.

\footnotetext{
${ }^{2}$ expected time during which the demand is greater than the available capacity of the power system
} 
Ekpenyong et al. (2012) and Suresh and Kumarappan (2013) gave outlines to schedule the power production. Ekpenyong et al. (2012) also considered ramp-rate constraints for the generating units. Other studies ensure for each period that the generating capacities that are not in maintenance are sufficient to cover the demand plus sometimes a reserve constraint.

\section{- Cost-based}

References : (Abirami et al., 2014; Al-Khamis et al., 1992; Anghinolfi et al., 2012; Baskar et al., 2003; Brandt et al., 2013; Buljubasic and Gavranovic, 2012; Burke and Smith, 2000; Canto, 2008; Charest and Ferland, 1993; Chattopadhyay, 1998; Digalakis and Margaritis, 2002; Ekpenyong et al., 2012; El-Amin et al., 2000; El-Sharkh et al., 2003; El-Sharkh, 2014; Fattahi et al., 2014; Fourcade et al., 1997; Frost and Dechter, 1998; Fu et al., 2007; Gardi and Nouioua, 2011; Godskesen et al., 2013; Gorge et al., 2012; Jost and Savourey, 2013; Khemmoudj et al., 2006; Kovács et al., 2011; Kralj and Petrovic, 1995; Leou, 2006; Lusby et al., 2013; Marwali and Shahidehpour, 1998, 1999a, 2000a; Mollahassani-pour et al., 2014; Mytakidis and Vlachos, 2008; Rozenknop et al., 2013; Saraiva et al., 2011; Satoh and Nara, 1991; Silva and Morozowski, 1995; Silva, 2000; Yellen and Al-Khamis, 1992).

The other common objective is to minimize the general operational costs. These are production costs (e.g., fuel consumption), maintenance costs (e.g., loss of profit), and sometimes unit start-up costs (Canto, 2008). The production costs depend on the generators' power output, so it is necessary to schedule their production level. An economic dispatch problem is usually solved with an objective of satisfying the demand at a minimum cost. The units with the lowest marginal costs are used to meet the system requirements; the other units produce only during the peak periods. Some studies address UC jointly to the GMS problem or/and take into account the transmission network (see Section 2.2). Other authors deal with a more specific problem including an accurate fuel management (Anghinolfi et al., 2012; Brandt et al., 2013; Buljubasic and Gavranovic, 2012; Fourcade et al., 1997; Gardi and Nouioua, 2011; Godskesen et al., 2013; Gorge et al., 2012; Khemmoudj et al., 2006; Jost and Savourey, 2013; Lusby et al., 2013; Rozenknop et al., 2013). We discuss this issue in more detail in Section 2.4.

\section{- Reliability-and-cost-based}

References : (Huang, 1997; Kralj and Petrovic, 1995; Muñoz-Moro and Ramos, 1999).

The literature reports on some studies dealing with objective functions that are based on both reliability and cost. For instance, Huang (1997); Kralj and Petrovic (1995); Muñoz-Moro and Ramos (1999) proposed multiobjective approaches to try to find the best trade-off between these two conflicting objectives. Among these examples, Muñoz-Moro and Ramos (1999) proposed a two-stage approach that first considers the operational costs and then the reserve margins.

\subsubsection{Deregulated power systems}

Deregulation changes the maintenance scheduling problem. The GENCOs and TRANSCOs are now usually responsible for maintaining their equipment. The ISO ensures the smooth running of the system in terms of reliability and security. Risk is managed by guaranteeing sufficient reserves of energy for each period to meet uncertainties in, for example, the demand or the generator deterioration. The different actors may have conflicting interests: GENCOs and TRANSCOs want to maximize their profits, whereas the ISO is concerned with demand satisfaction and congestion avoidance. For example, GENCOs tend to perform maintenance when the energy price is at its lowest, which may make it difficult to meet the demand. Thus, in an iterative way (see Figure. 3), the GENCOs and TRANSCOs submit their preferred maintenance schedules to the ISO, which verifies the acceptable behavior of the system on the basis of all the market-player information. If the ISO 
is not satisfied, it will request modifications (e.g., the rescheduling of one or more maintenance tasks). The coordination procedure may vary from one system to another.

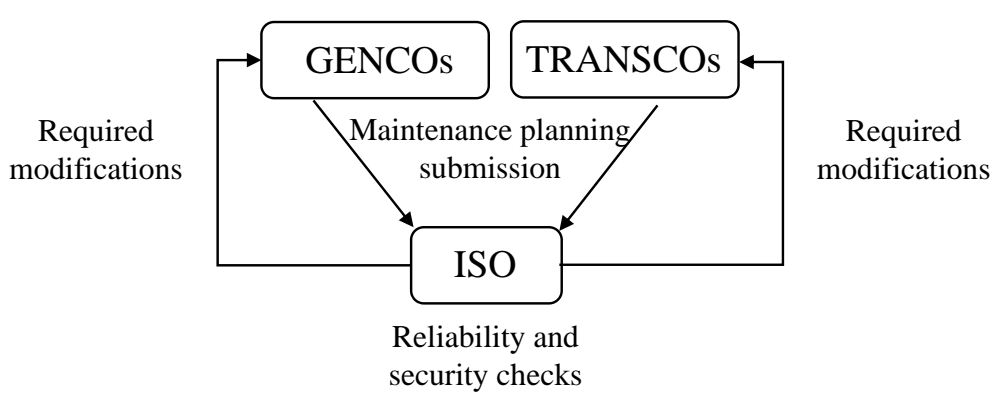

Figure 3: Coordination procedure in a deregulated power system

Since the opening up to competition, the GMS problem in deregulated power systems has been widely studied (Badri and Niazi, 2012; Barot and Bhattacharya, 2008; Billinton and Abdulwhab, 2003; Bisanovic et al., 2011; Chattopadhyay, 2004b,a; Conejo et al., 2005; Elyas et al., 2013; Eshraghnia et al., 2006; Feng et al., 2009; Fu et al., 2007; Geetha and Shanti Swarup, 2009; Han et al., 2011; Kim et al., 2005; Marwali and Shahidehpour, 1999a,b, 2000b,a; Min et al., 2013; Wu et al., 2008; Zhan et al., 2014). The problem has globally the same constraints as for the vertically integrated case. Bisanovic et al. (2011) introduced bilateral contracts (defined through prices and power quantities to supply) in their model. Chattopadhyay (2004b); Marwali and Shahidehpour (1999b, 2000a) considered fuel based constraints. Indeed, restrictions on the maximum fuel supplied each week, month, and year may arise due to contractual agreements with fuel suppliers. As noted for regulated power system, the output levels of the generating units may be computed for each period. It allows for the more accurate estimation of the revenues and operating costs and can be required, among others, by the introduction of network constraints. In some studies (Badri and Niazi, 2012; Fu et al., 2007; Marwali and Shahidehpour, 1999a,b, 2000b,a), cost minimization is still the objective. These studies generally deal with a security-constrained GMS problem operating under a pool-based model or a regulated monopoly. However, profit maximization is a much more common objective (Barot and Bhattacharya, 2008; Bisanovic et al., 2011; Chattopadhyay, 2004b,a; Conejo et al., 2005; Elyas et al., 2013; Eshraghnia et al., 2006; Feng et al., 2009; Geetha and Shanti Swarup, 2009; Kim et al., 2005; Min et al., 2013; Wu et al., 2008; Zhan et al., 2014). Note that these two objectives are different because profits depend on both costs and revenues. A very recent study by Dahal et al. (2015) explains how maintenance costs can be precisely modeled in deregulated markets considering, among others: failures, contractual compensations, rescheduling, and market opportunities. The authors demonstrated the importance and the impact of market related costs in maintenance schedules.

Under deregulation, the GENCOs have limited information about the system. The coordination of the decisions and information exchange between the GENCOs and the ISO are important. The interactions between these two actors have received intensive interest (Barot and Bhattacharya, 2008; Conejo et al., 2005; Elyas et al., 2013; Eshraghnia et al., 2006; Geetha and Shanti Swarup, 2009; Han et al., 2011; Min et al., 2013; Zhan et al., 2014). Reliability-based objectives are considered when the problem is solved from the point of view of the ISO: maximizing the reserve throughout the horizon (Eshraghnia et al., 2006), maximizing the sum of the ratio of the net reserves to the gross reserves by period (Conejo et al., 2005), minimizing the standard deviation of this last ratio (Zhan et al., 2014), or minimizing a risk penalty factor related to an adequate level of reliability (Geetha and Shanti Swarup, 2009). Cost minimization is considered in (Barot and Bhattacharya, 2008). Barot and Bhattacharya (2008); Conejo et al. (2005); Eshraghnia et al. (2006); Geetha and Shanti Swarup (2009); Min et al. (2013) presented iterative coordination methods based on rescheduling signals. Eshraghnia et al. (2006) suggested a coordination procedure where at every iteration the ISO indicates permissible and 
impermissible maximum power for the maintenance of the generating units in each period. In the same way, Barot and Bhattacharya (2008) coordinated the decisions through corrective signals sent by the ISO to the GENCOs, indicating the maximal capacities that can be in maintenance during critical periods. These signals are calculated according to the responsibility of each GENCO for not supplying the load. These capacity-based signals can be replaced by penalties and/or incentive signals. Conejo et al. (2005); Geetha and Shanti Swarup (2009); Min et al. (2013) penalized periods of maintenance during peak periods or when the reliability of the system is uncertain. The objective function associated with the GENCO problem is modified at each iteration to represent the ISO's recommendations. In Conejo et al. (2005), GENCOs that adjust their maintenance plans are paid to offset their losses compared to their initial plans; the cost is paid by the customers. Han et al. (2011) proposed an ISO coordination procedure to adjust the individual generator-maintenance schedules according to the preferences of each GENCO, while guaranteeing system reliability. Elyas et al. (2013) gave the ISO the responsibility for maintenance scheduling. They took into account consumer satisfaction by maximizing the annual social welfare and also consider the profit-seeking GENCOs. They suggested a maintenance bidding approach to model the coordination mechanism. Finally, Zhan et al. (2014) analyzed the relationship between the ISO and the GENCOs in GMS using a multiobjective approach.

\subsection{Transmission maintenance scheduling and network considerations}

Along with generator maintenance, transmission-line maintenance must be scheduled. This problem, usually called the transmission maintenance scheduling (TMS) problem, has received less attention than the GMS problem (Abirami et al., 2014; Fu et al., 2007; Geetha and Shanti Swarup, 2009; Langdon and Treleaven, 1997; Lv et al., 2012; Marwali and Shahidehpour, 1998, 1999b, 2000b). It is necessary to ensure that taking a line out for maintenance does not impact the network reliability and security. The TMS constraints are globally the same as those for GMS (e.g., time windows for maintenance tasks, resource requirements, demand satisfaction). These are also constraints on the line capacity and may include voltage considerations. The network can be modeled as either a transportation model (Abirami et al., 2014; Marwali and Shahidehpour, 1998, 1999b) or a more complex but more realistic DC power flow model ${ }^{3}$ (Fu et al., 2007; Geetha and Shanti Swarup, 2009; Langdon and Treleaven, 1997; Lv et al., 2012; Marwali and Shahidehpour, 2000b).

The TMS problem can be addressed independently from the GMS problem (Langdon and Treleaven, 1997; Lv et al., 2012; Marwali and Shahidehpour, 2000b). In this approach, the state of the network appears as a constraint during the resolution of the GMS problem. Although this approach is especially valid for regulated systems it may also apply to deregulated power systems. For instance, Marwali and Shahidehpour (2000b) looked for a trade-off between maintenance costs and loss of revenue over a short-term horizon.

When the TMS problem is tackled jointly with the GMS problem (Abirami et al., 2014; Fu et al., 2007; Geetha and Shanti Swarup, 2009; Marwali and Shahidehpour, 1998, 1999b), it becomes more complex. The maintenance must take into account economic considerations while minimizing the unsatisfied demand. The GMS and TMS problems have been solved generally on a monthly or weekly basis. Marwali and Shahidehpour (1998) coordinated maintenance decisions over a long-term horizon. Marwali and Shahidehpour (1999b) included fuel and emission constraints in the problem, considering local transmission lines within a GENCO. Fu et al. (2007) proposed an optimal coordination approach between generation and transmission outages, midterm maintenance outage and hourly security constrained generation scheduling. The technique can be used by a company in a monopoly position or by an ISO. Abirami et al. (2014) solved the integrated maintenance scheduling problem on hourly basis and consider partial maintenance for transmission lines. When deregulated power systems are based on the power exchange model, the GENCOs and TRANSCOs are profit-oriented and do not have global information about the state of the system. As explained earlier, the ISO has to coordinate

\footnotetext{
${ }^{3}$ Linearization of an AC power flow model
} 
the submitted schedules; the cheapest transmission lines and generators might be overloaded. To our knowledge, only one study applies to this case ; Geetha and Shanti Swarup (2009) solved the problem for every actor (ISO, GENCOs, and TRANSCOs) and coordinate the decisions through penalties.

Network considerations and especially coordination between GMS and TMS problems are important to maintain the security as well as the efficiency of the global system. If the TMS problem is not solved jointly with the GMS problem, network constraints can be introduced when the latter problem is solved (Badri and Niazi, 2012; Barot and Bhattacharya, 2008; Chattopadhyay, 1998; Chen and Toyoda, 1991; El-Sharkh et al., 2003; Leou, 2006; Marwali and Shahidehpour, 2000a, 1999a; Silva and Morozowski, 1995; Silva, 2000; Wu et al., 2008). These constraints can implicitly include the maintenance tasks planned for the network. Maintenance and unit commitment decisions must never exceed the line capacities. To our knowledge, Chen and Toyoda (1991) were the first to consider these constraints in a multi-area problem, but they did not handle unexpected breakdowns. The transportation model is widely used, except by Silva (2000) who modeled a DC power flow.

\subsection{Management of uncertainty}

Uncertainty in GMS and TMS can be significant and it requires specific management. Indeed, the load curve and the fuel and energy prices may be difficult to estimate precisely. Furthermore, corrective maintenance, characterized by unexpected breakdowns, has a real impact on the production. Uncertainty has therefore to be handled with care.

Reserve constraints can help to deal with these risks. Reliability objectives, as discussed earlier, can also be used. However, using only deterministic strategies may be inappropriate in the case of large disturbances.

To explicitly consider unexpected breakdowns, researchers associate a forced outage rate (FOR) with generating units or transmission lines. The FOR represents the probability that equipment will not be available for service when required. It impacts the quantity of energy that can be supplied. Thus, it prevents unsuitable maintenance schedules when load constraints are considered. One can also (artificially) reduce the capacity of the generators and solve a deterministic problem, but the not-supplied energy can be overestimated. However, the use of stochastic reliability indices such as the expected energy not served or EENS(Baskar et al., 2003; Chattopadhyay, 2004b; Geetha and Shanti Swarup, 2009; Lv et al., 2012; Marwali and Shahidehpour, 1999a,b; Silva and Morozowski, 1995; Yellen and Al-Khamis, 1992) and the loss of load probability (LOLP) (Billinton and Abdulwhab, 2003; Han et al., 2011; Mohanta et al., 2004, 2007; Reihani et al., 2012; Suresh and Kumarappan, 2013; Volkanovski and Mavko, 2008) is better suited to tackle problems in this scenario. The EENS is minimized or a threshold for acceptability is defined. Satisfying EENS within a specific threshold results in an acceptable LOLP. Authors such as Mohanta et al. (2007); Reihani et al. (2012); Suresh and Kumarappan (2013) considered the LOLP reliability index in a stochastic levelized risk method. The first step of this technique is to build an outage capacity probability table (COPT) by associating a probability to every generation capacity level taking into account the forced outage rate of each generating unit. The table can be computed with a convolution algorithm. The second step consists in finding the system's risk characteristic coefficient, defined as the change of the generating units outage capacity in MW when the systems risk changes by a certain factor. Each unit capacity is then replaced by an effective load carrying capacity based on the system's risk characteristic coefficient and the FOR. It represents the actual capacity of the units which is used for meeting the load demand. Similarly, the load of each interval is replaced by a value, called the equivalent load, which takes into account the peak variation during this interval and the system's risk characteristic coefficient. Leveling the risk may be finally realized by minimizing the sum of the squares of the reserves in the planning period. The reserve in each interval is obtained by subtracting the effective load carrying capacity of the available generating units and the equivalent load. In Mohanta et al. (2007), the risk associated with the resulting plan is evaluated by giving a confidence interval for the LOLP. Suresh and Kumarappan (2013) presented a coordination scheme to minimize the LOLP and the deviations of annual supply reserve ratio by considering 
the system's risk characteristic coefficient as a control parameter of their approach. We refer the reader to the previous given references for more details. As a fairly closed approach, Volkanovski and Mavko (2008) chose to minimize directly the annual value of the LOLE. Billinton and Abdulwhab (2003) discussed a health levelization technique over a short-term horizon. Incorporated in a probabilistic framework, the objective is to maximize the health/security of the system, defined as the probability that the available reserves are greater than the required reserves. Chattopadhyay (2004b) simulated random outages using the Monte Carlo technique and proposes a stochastic optimization framework based on a game theory model to tackle the GMS problem. In Geetha and Shanti Swarup (2009); Lv et al. (2012); Marwali and Shahidehpour (1999a,b, 2000a); Silva and Morozowski (1995), a probabilistic approach takes FOR into account in a problem with network constraints. Last but not least, Feng et al. (2009) analyzed the impact of unexpected unit failures on the GMS solution and especially on: maintenance periods, producer benefits, maintenance costs and the costs of repairing or replacing some generating units. A modified superposed power law process models the unit failure rate. Its parameters are determined via the Gauss-Newton algorithm.

Fuzzy logic theory is also used to handle some data uncertainties in (Huang, 1997; Dahal et al., 1999; El-Sharkh et al., 2003; Mohanta et al., 2004). It allows the representation and the use of linguistic knowledge. This concept is mainly used through fuzzy fitness function in a genetic algorithm (GA). Huang (1997) used triangular and trapezoidal membership functions for the multiple objectives (reserve margin, production cost) and for the soft constraints (manpower, time windows, geographical constraint). They used a GA to tune the membership functions. Dahal et al. (1999) introduced a fuzzy evaluation function combining the reliability objective function, the manpower constraint and a penalty factor associated with the inflexible demand satisfaction constraint. Based on their experience, they used triangular and trapezoidal membership functions to define the fuzzy sets. Mohanta et al. (2004) incorporated uncertainty associated to the data and the forced outage rate by evaluating the reliability of power plants using fuzzy theory. They used a fuzzy LOLP to assess the quality of the method. The drawback of the fuzzy logic approach is the intensive need of expert knowledge and substantial amounts of data.

The power demand may also be uncertain. Its stochastic nature can be explicitly considered. A set of scenarios that model alternative demands is used in (Anghinolfi et al., 2012; Brandt et al., 2013; Buljubasic and Gavranovic, 2012; Canto, 2008; Canto and Rubio-Romero, 2013; Gardi and Nouioua, 2011; Godskesen et al., 2013; Gorge et al., 2012; Jost and Savourey, 2013; Lusby et al., 2013; Rozenknop et al., 2013). The maintenance decisions ensure that the demand is met in all the scenarios. El-Sharkh et al. (2003) simulated the demand and the cost uncertainties using triangular membership functions defining fuzzy sets. Ekpenyong et al. (2012) presented an effective method, called model predictive control, that detects demand disturbances and makes appropriate corrections.

When the objective is profit-based, it may be necessary to take into account the volatility of market prices. Wu et al. (2008) used a stochastic model based on an hourly price-based unit commitment. The hourly electricity and fuel prices are modeled as a set of scenarios determined via a Monte-Carlo method.

\subsection{Fuel management and maintenance scheduling}

Thermal production represents around $80 \%$ of the total global electricity production ${ }^{4}$. Fuel is fundamental for the effective functioning of these plants, therefore it can be subject to a specific management. In Badri and Niazi (2012), the fuel consumption is limited by period for every generating unit. If fuel shortages occur, energy can be purchased externally. In Wu et al. (2008), the fuel allocations, which depend on a predetermined contract with a supplier, are limited by group of units.

\footnotetext{
${ }^{4}$ The shift project data portal - Browse energy and climate data, http://www.tsp-data-portal.org/Breakdown-of-ElectricityGeneration-by-Energy-Source, last accessed : 2015-05-07
} 
A bigger challenge comes with refueling considerations. Few studies handle this problem. In some cases, refueling can be done continuously without significantly affecting production (Al-Khamis et al., 1992; Chattopadhyay, 1998, 2004b; Marwali and Shahidehpour, 1999b, 2000a; Muñoz-Moro and Ramos, 1999), but sometimes (e.g., for nuclear reactors) it can occur only when the generators are offline (Anghinolfi et al., 2012; Brandt et al., 2013; Buljubasic and Gavranovic, 2012; Fourcade et al., 1997; Gardi and Nouioua, 2011; Godskesen et al., 2013; Gorge et al., 2012; Khemmoudj et al., 2006; Jost and Savourey, 2013; Lusby et al., 2013; Rozenknop et al., 2013). The introduction of fuel management into the GMS problem increases its complexity, but also makes it more realistic. Al-Khamis et al. (1992) focused on the case of fuel constraints for each generating unit. Muñoz-Moro and Ramos (1999) are concerned with the maximum fuel storage capacities of thermal plants. Marwali and Shahidehpour (1999b, 2000a) solved a fuel dispatch problem with multiple suppliers. The fuel consumption is limited by week, month, and year and is linked with the output level of the generators. The coordination of long-term and short-term decisions is discussed in (Marwali and Shahidehpour, 2000a). Chattopadhyay (1998) discussed coal supply management with different transport modes from the mine to the power stations. In Chattopadhyay (2004b), the author introduced fuel contracts with suppliers (with fixed fuel prices and volumes) in a GMS model and describes a successive linearization scheme to approximate the fuel consumption as a linear function. Two other studies (Fourcade et al., 1997; Khemmoudj et al., 2006) are concerned with planning shutdowns in production to carry out refueling and maintenance operations; the fuel quantity to supply is known in advance.

A challenge submitted jointly by $\mathrm{EURO}^{5}$ and $\mathrm{ROADEF}^{6}$ in collaboration with $\mathrm{EDF}^{7}$ has renewed interest in this latter problem. It presents a large-scale energy management problem with many constraints (Porcheron et al., 2010). The time horizon is long and fine-grained (up to 277 weeks with 7 or 21 timesteps per week). Two types of production units are considered. Non-nuclear plants can refuel continuously whereas nuclear plants must be shut down when fuel is supplied. In contrast to previous studies (Fourcade et al., 1997; Khemmoudj et al., 2006), the amount of fuel that is supplied for every nuclear plant is left as a decision variable. Furthermore, the production levels for the plants have to be planned under demand uncertainty modeled by a set of scenarios (up to 500). The objective is to plan the production and refueling while minimizing the production costs of non-nuclear plants and the refueling costs of nuclear plants. The problem has been proved to be NP-hard (Godskesen et al., 2013). Almost twenty teams participated in this challenge, and some of them (Anghinolfi et al., 2012; Brandt et al., 2013; Buljubasic and Gavranovic, 2012; Gardi and Nouioua, 2011; Godskesen et al., 2013; Jost and Savourey, 2013; Lusby et al., 2013; Rozenknop et al., 2013) published their results. This problem has also been considered by Gorge et al. (2012) with some simplifications. The problem is often decomposed into several components: planning of the refueling, computation of the refuel amounts, and planning of the production.

\subsection{Benchmarks}

Publicly accessible data to test optimization algorithms for maintenance scheduling in electricity systems are rather scarce. Probably the most classical instance is the IEEE $^{8}$ Reliability Test System (IEEE-RTS) published in 1979 (Reliability Test System Task Force of the Application of Probability Methods Subcommittee, 1979) and released in 1996 (Reliability Test System Task Force of the Application of Probability Methods Subcommittee, 1999). The IEEE-RTS includes data on the network, the generating units, the demand, and the costs. This benchmark has been used in several articles (Badri and Niazi, 2012; Billinton and Abdulwhab, 2003; Elyas et al., 2013; Eshraghnia et al., 2006; Fattahi et al., 2014; Feng et al., 2009; Geetha and Shanti Swarup, 2009; Marwali and Shahidehpour, 1998, 1999a,b, 2000a; Mollahassani-pour et al., 2014; Schlünz and van Vuuren,

\footnotetext{
${ }^{5}$ Association of European Operational Research Societies

${ }^{6}$ Société française de recherche opérationnelle et d'aide à la décision

${ }^{7}$ Electricité de France

${ }^{8}$ Institute of Electrical and Electronics Engineers
} 
2013; Suresh and Kumarappan, 2013; Zhan et al., 2014). Another commonly used set of instances contributed by the IEEE $^{9}$ represent portions of the North American electricity system; this set served as a benchmark in Abirami et al. (2014); El-Sharkh et al. (2003); El-Sharkh (2014); Fu et al. (2007); Marwali and Shahidehpour (2000b). Additionally, an instance with 21 generation units described by Yamayee et al. (1983) regularly serves as a test case (Baskar et al., 2003; Dahal et al., 1999; Dahal and Chakpitak, 2007; Ekpenyong et al., 2012; Schlünz and van Vuuren, 2013; Suresh and Kumarappan, 2013; Yare and Venayagamoorthy, 2010). Data associated with real cases are often used to validate proposed techniques. However, to our knowledge, the only publicly available data is that published of the EURO-ROADEF-EDF challenge (Porcheron et al., 2010).

\section{Solution methods}

Various heuristic and exact approaches have been proposed for the GMS and/or TMS problems. The solution techniques mainly focus on metaheuristics and mathematical programming. This section provides details about all these techniques and discusses their applicability to the problems defined in the previous sections. To provide a global overview, Table.2 classifies the references according to the solution method they apply.

\subsection{Mathematical programming approaches}

Mathematical programming methods are essentially based on dynamic programming, pure mixed-integer programming, branch-and-bound, Lagrangian relaxation, and Benders decomposition.

Until the 90s, dynamic programming has been often used for solving the GMS problem because of its sequential decision process. For instance, Huang (1997) combined dynamic programming with fuzzy logic in a multiobjective problem. However, the "curse of dimensionality" limits the application of this method (Yamayee, 1982).

Alternatively, many mixed integer programming models are proposed for the GMS and TMS problems. Objectives and constraints widely vary from one study to another; a clear indicator of the difficulty to point out a general model. Only linear models are likely to be handled by commercial solvers and only small or medium-size instances can be efficiently solved. Badri and Niazi (2012); Barot and Bhattacharya (2008); Bisanovic et al. (2011); Canto and Rubio-Romero (2013); Chen and Toyoda (1991); Conejo et al. (2005); Fourcade et al. (1997); Kovács et al. (2011); Mollahassani-pour et al. (2014); Muñoz-Moro and Ramos (1999); Wu et al. (2008) formulated mixed integer linear programming (MILP) models and solved them combining branch-and-bound with the simplex method or interior-point methods. Among studies based on multiobjective optimization, Kralj and Petrovic (1995) designed a custom branch-and-bound, and Muñoz-Moro and Ramos (1999) proposed a two-stage goal programming approach solved by branch-and-bound.

The direct use of mixed integer programming is sometimes unsuitable as the computational time grows prohibitively with problem size. To overcome this drawback, decomposition techniques can be applied. The most studied technique is the Benders decomposition which allow to decouple a large-scale problem into a master problem and one or several independent small-scale subproblems which are easier to solve. The master problem works only with a subset of the variables and the constraints. Infeasibility cuts are generated in the master problem to ensure that the subproblem constraints are satisfied. Optimality cuts are also introduced if some parts of the objective are related to the subproblems. The resulting algorithm iteratively solves the master problem and the subproblems until it converges or concludes that there is no solution. For more details, the reader is invited to consult the original paper (Benders, 1962). This decomposition technique applies particularly well to the GMS problem because of the problem's intrinsic two-stage structure. The master problem is concerned only with the constraints regarding the scheduling of the maintenance tasks as well as the

\footnotetext{
${ }^{9}$ University of Washington Electrical Engineering, Power systems case archive, http://www.ee.washington.edu/research/pstca/, last accessed : 2015-04-08
} 
resources requirement if needed. Load and network constraints, as well as fuel management, are moved to the subproblems. Benders decomposition is applied for both regulated (Al-Khamis et al., 1992; Canto, 2008; Fu et al., 2007; Marwali and Shahidehpour, 1998, 1999a; Silva and Morozowski, 1995; Silva, 2000; Yellen and AlKhamis, 1992) and deregulated (Fu et al., 2007; Geetha and Shanti Swarup, 2009; Marwali and Shahidehpour, 1999b, 2000a) power systems. Lv et al. (2012) introduced modified Benders feasibility cuts. They also define an index of critical lines - related to the system reliability - to reduce the computational complexity and the solution time. Marwali and Shahidehpour (2000a) coordinated long-term and short-term generation decisions with a dynamic scheduling algorithm. They used a Benders decomposition to define the maintenance decisions and an augmented Lagrangian relaxation to solve the underlying unit commitment. The same authors proposed also a deterministic (Marwali and Shahidehpour, 1998) and a probabilistic (Marwali and Shahidehpour, 1999a) Benders based approach to jointly schedule the generation and transmission maintenance.

Mathematical programming may be coupled with heuristic approaches. For instance, linear programming has been used in combination with local search (Gardi and Nouioua, 2011), genetic algorithms (Feng et al., 2009), and custom heuristics (Jost and Savourey, 2013). Examples of the latter include the work of Rozenknop et al. (2013) who combined column generation with customized heuristics, and that of Gorge et al. (2012) who applied a technique based on semidefinite programming, followed by a randomized rounding procedure.

It is worth noting that mathematical programming does not seem to be better adapted to one or other of problems discussed in the previous sections. However, all the methods presented in this part are mainly suitable when only linear objectives and constraints are considered in the GMS and/or TMS problems. Therefore, they cannot be used with the main reliability criterion (i.e. the minimization of the square of the reserves) or with quadratic cost functions.

\subsection{Heuristics and metaheuristics}

Due to the NP-hardness of the maintenance problems faced in power systems and the size of real-word instances, heuristic techniques have been largely developed. These methods also allow for more flexibility to deal with non linear or very complex constraints and/or objectives.

\subsubsection{Genetic algorithms}

GAs are widely used for solving the GMS problem due, mainly, to the structure of the decisions that are made. These algorithms are inspired by natural evolution. A population of abstract representations of solutions, called individuals, evolves through an iterative process toward better solutions. Solutions are usually encoded to facilitate the application of the several techniques used in GAs such as selection, mutation and crossover. In the particular case of GSM, different coding methods have been considered. In the binary representation, an individual has $\mathrm{G} \times \mathrm{T}$ genes (where $\mathrm{G}$ is the number of generating units and $\mathrm{T}$ is the number of periods) and the value of gene $(\mathrm{g}, \mathrm{t})$ is set to 1 if unit $\mathrm{g}$ starts maintenance at time $\mathrm{t}$, and 0 otherwise. In the integer representation, a individual has $\mathrm{G}$ genes and the value of gene $\mathrm{g}$ corresponds to the maintenance starting period of generating unit g. Binary or gray encoding of the latter values may also be used. Dahal and McDonald (1997) showed that integer-coding is the most efficient encoding strategy since it generates the smallest search space. Moreover, the integer coding reduces the probability of infeasibility during the process, and it avoids the overhead necessary to code and decode a solution. Baskar et al. (2003) revisited the binary for integer representation, the real encoding (using real values instead of integer values), and the classic integer encoding. For their experiments, integer coding proves to be the best independently of the problem size. Wang and Handschin (2000) and Reihani et al. (2012) reached the same conclusions about the efficiency of integercoding. Despite these findings, binary coding is still used in some approaches (Eshraghnia et al., 2006; Leou, 2006; Mohanta et al., 2004, 2007; Suresh and Kumarappan, 2013). Finally, Volkanovski and Mavko (2008) 
introduced a completely different encoding strategy that uses real values between 0 and 1 obtained by dividing the maintenance starting time value by the number of periods of the horizon.

Needless to say, contrary to solution encoding, the fitness function associated to every individual is problem dependent. Usually, it includes penalties associated with the violations of some constraints. Fuzzy models may be developed to handle data uncertainties (see Section 2.3) through the use of fuzzy evaluation functions.

Being population-based metaheuristics, GAs require initial solutions to built the initial population. The literature reports on randomly generated solutions (Dahal et al., 1999; Huang, 1997; Leou, 2006; Mohanta et al., 2004, 2007; Reihani et al., 2012) and heuristically generated solutions (Burke and Smith, 2000; Dahal and Chakpitak, 2007; Volkanovski and Mavko, 2008). The latter are often built using constructive methods that are mainly based on the following process: ranking generating units in order of decreasing capacity, and iteratively schedule the maintenance of the units when the demand is at its lowest level, while satisfying the constraints of the model. GAs try to improve solutions by applying the classic operators such as tournament or roulette wheel selection, one or two-point crossovers, random mutation and a replacement policy based usually on elitism. To reduce the probability of trapping in local optima, Dahal and Chakpitak (2007); Mohanta et al. $(2004,2007)$ accepted non-improving solutions at each iteration according to the probabilistic acceptance criterion of simulated annealing. Langdon and Treleaven (1997) designed a GA to schedule the maintenance of the transmission lines combined with some greedy heuristics. Some GAs include a local search algorithm for improving the quality of the solutions. Neighborhoods are usually defined by changing the maintenance starting time of a randomly selected generator. Burke and Smith (2000) tested the combination of a genetic algorithm with several local search methods : a basic hill climbing technique, a simulated annealing, and a tabu search. Hybridization with tabu search proved to be the most efficient approach in their experiments. El-Sharkh et al. (2003) maintained feasibility using a hill climbing technique during the solution process. Leou (2006) executed simulated annealing for each individual solution of the population. Reihani et al. (2012) designed an hybrid algorithm based on extremal optimization and a GA.

GAs are mostly used in regulated power systems; they allow dealing with the non linearity of the main reliability-based objectives.

\subsubsection{Particle swarm optimisation}

Recent studies (Ekpenyong et al., 2012; Suresh and Kumarappan, 2013; Yare and Venayagamoorthy, 2010) applied the particle swarm optimisation (PSO) to the GMS problem. PSO is another population-based metaheuristic which bares many similarities with GAs. It simulates the social behaviour of birds within a flock, or even fishes within a school evolving by information exchange. The population is composed of particles moving in the search space of the optimization problem. The position of a particle represents a candidate solution. Each particle is guided according to the best solution (fitness) it has achieved so far, and according to the current best particle, or particles if multiple swarms are considered. On its original version, PSO handles only continuous variables; however, Ekpenyong et al. (2012) introduced a penalty function to deal with the discrete nature of the variables involved in the GMS problem. Suresh and Kumarappan (2013) chose to test a particular binary version of PSO. They defined the particle according to the capacity outage probability table. To improve the effectiveness of the algorithm, they applied crossover and mutation operators to some particles during the iterative process. Yare and Venayagamoorthy (2010) considered only the latter operator in a multiple swarms-modified discrete PSO where information sharing is enhanced by using multiple populations. Non linear reliability-based objectives (Suresh and Kumarappan, 2013; Yare and Venayagamoorthy, 2010) and cost-based objectives (Ekpenyong et al., 2012) of regulated power systems have been tackled using PSO. 


\subsubsection{Other populations-based methods}

Apart from GAs and PSO, other population-based techniques have been explored in the literature. The first three studies deal with regulated power systems and are concerned with the maintenance and generation costs.

Digalakis and Margaritis (2002) applied a parallel co-operating cultural algorithm to solve the GMS problem. Contrary to GAs, this method considers multiple populations, but it uses similar operators (selection, crossover, mutation). The exchange of individuals between the populations allows to guide the algorithm towards the promising areas of the search space. The authors used local search to improve the quality of the solutions after the initialization and the application of the genetic operators.

El-Sharkh (2014) tested a clonal selection algorithm (CSA) to schedule the maintenance in a regulated power system. CSA imitates the mechanisms of the adaptive immune system. From a population of individuals randomly generated, all infeasible individuals are repaired using a hill climbing algorithm. The best individuals are then cloned and a mutation operator is applied to these copies. The hill climbing technique is used again to repair them. According to the outages planning, an economic load dispatch problem is solved within the process. This algorithm is also used for deregulated power systems in (Elyas et al., 2013).

Recently, Abirami et al. (2014) presented a teaching-learning based optimization algorithm (TLBO) for solving the GMS problem. This technique is inspired by the transfer of knowledge between teacher and students in the classroom. TLBO is a population-based iterative learning algorithm. However, it does not use genetic operations like selection, crossover, and mutation but tries to improve individuals based on their interaction with the teacher and the communication with the other individuals. The population is initialized by randomly setting the starting period for the maintenance of the generators and the transmission lines. The best individual is deemed as the teacher. Other individuals are modified to move towards the teacher.

Finally, Zhan et al. (2014) proposed an approach based on a novel evolutionary algorithm called group search optimizer inspired by animal searching behaviour. They computed a set of Pareto-optimal solutions for a multiobjective problem based on reliabiliy, costs, and profits.

\subsubsection{Simulated annealing}

Simulated annealing (SA) is a stochastic metaheuristic inspired by the annealing process in metallurgy. At each iteration, SA randomly generates a neighbor of the current solution. The algorithm accepts non-improving solutions according to some probability, allowing the search to escape local optima. These probability decrease as the number of iterations increases. SA has been used as the main approach to solve the GMS problem in (Burke and Smith, 2000; Dahal and Chakpitak, 2007; Fattahi et al., 2014; Han et al., 2011; Saraiva et al., 2011). Fattahi et al. (2014) used in addition custom heuristics to solve the underlying UC. Saraiva et al. (2011) built new solutions by randomly selecting a generating unit and setting a new random maintenance starting time for it. At each iteration, Han et al. (2011) selected first the unit with a weighted roulette wheel where weights are fixed according to the LOLP associated with each generator, and then change randomly its maintenance starting time. SA has been also combined with other techniques. For instance, Anghinolfi et al. (2012) hybridized SA and linear programming; Godskesen et al. (2013) coupled a SA and constraint programming; and Burke and Smith (2000); Dahal and Chakpitak (2007); Mohanta et al. (2004, 2007); Leou (2006) embedded a SA into a GA. SA has been mainly used to solve problems arising in the regulated power systems.

\subsubsection{Tabu search}

Tabu search (TS) is a local search-based metaheuristic that avoids revisiting solutions by recording the recent history of the search in a short-time memory called tabu list. To escape local optimum, non improving solutions are accepted during the algorithm. To our knowledge, TS has only been applied to solve the GMS problem 
in regulated power systems. Burke and Smith (2000) found better computational results when TS is used as a local search embedded in a GA. The neighborhoods are those described in the Section 3.2.1. El-Amin et al. (2000) applied TS by randomly selecting a generator and modifying its maintenance starting time.

\subsubsection{Ant colony optimization}

Ant colony optimization (ACO), a constructive metaheuristic inspired by the behavior of ant colonies, has been also applied to solve the GMS problem in regulated power systems with a cost-based objective (Foong et al., 2007; Fattahi et al., 2014; Mytakidis and Vlachos, 2008). The algorithm builds solutions incrementally by selecting a maintenance starting period for each generator. The selection process is based on the combination of pheromone level, related to the number of times the component has been selected, and some greedy heuristics. Fattahi et al. (2014) combined ACO with some sub-algorithms to deal with a complex problem based on operational hours. According to the outages fixed in the previous phase, UC is solved by a custom heuristic which proves to be better in their experiments than a GA.

\subsection{Constraint programming}

Constraint programming $(\mathrm{CP})$ is particularly useful for highly constrained problems. It is a powerful and flexible tool which makes express complex constraints relatively easy. It applies particularly well to the ROADEF challenge where maintenance tasks faced a variety of constraints such as overlapping, spacing, and incompatibility (Buljubasic and Gavranovic, 2012; Godskesen et al., 2013; Brandt et al., 2013). Brandt et al. (2013) coupled CP to a greedy heuristic to solve the unit commitment and the refueling problems. Buljubasic and Gavranovic (2012) presented a heuristic approach combining a constraint satisfaction problem to both a local search based on the marginal cost and a constructive optimization algorithm. Godskesen et al. (2013) used it with a local search and a greedy heuristic in a 3-phase algorithm. For a quite similar problem, Khemmoudj et al. (2006) proposed an approach combining constraint programming and local search.

$\mathrm{CP}$ is less suitable when the main objective of the problem is to find near-optimal solutions. Therefore, it has been scarcely used for solving the GMS problem. Frost and Dechter (1998) iteratively applied constraint programming to solve a cost bound problem; learning constraints are added to improve the efficiency of the algorithm.

\subsection{Game theory}

Game theory-based approaches have been explored on the problem arising in deregulated power systems (Chattopadhyay, 2004a; Kim et al., 2005; Min et al., 2013). These approaches are especially suitable since every GENCO tries to predict its competitors actions so as to stay one step ahead. The strategies adopted by the GENCOs are defined by a Nash equilibrium of the game.

\section{Conclusion and perspectives}

The GMS and TMS problems are the two main maintenance scheduling problems in the electricity industry. The constraints concern the maintenance tasks (time windows, incompatibility, sequence), the resource requirements, the reliability, and the demand satisfaction. Sometimes, e.g., for nuclear power plants, fuel consumption management is required. The GMS and TMS problems can be solved jointly or network constraints can be introduced into the former. Production planning is often incorporated into GMS, especially over a short-term horizon. This results in a complex problem that is generally NP-hard.

Maintenance scheduling is a major challenge in the electricity industry, especially since the liberalization of the electricity market. The objectives of regulated power systems are based mainly on the reliability (leveling, 
maximization of net reserves) and the costs (minimization of the operational costs). These objectives are not necessarily suitable for deregulated systems. It may be more appropriate to maximize the profits of the GENCOs and to coordinate the decisions of the various actors. The objectives of regulated systems remain relevant to the ISO - the actor that must ensure system reliability and security - but may conflict with the goals of the other actors (GENCOs, TRANSCOs, DISCOs). A Multiobjective optimization is thus a future solution framework.

Many solution methods have been proposed for the GMS and/or TMS problems. They include heuristics, metaheuristics (genetic algorithms, particle swarm optimization, simulated annealing, tabu search,ant colony optimization), hybrid approaches, mathematical programming (dynamic programming, MILP, branch-andbound, Benders decomposition), constraint programming, game theory. As the problem complexity increases making frontal resolution impracticable, the use of decomposition techniques become more and more relevant.

To the best of our knowledge, some problems have not yet been investigated. These include load uncertainty and price volatility when the TMS problem is solved jointly with the GMS problem or where coordination is needed between the GENCOs and the ISO. Apart from that, the growing renewable energy industries and its stochastic nature have an impact on the planning in power systems. Maintenance decisions in wind industry are very complex since the weather has a huge impact on the possible concrete realization of the scheduled tasks. Moreover, wind predictions can only be established in a very short term horizon. To explicitly handle these uncertainties via stochastic programming approaches may lead to substantial energy and cost savings. Taking into account numerous unexpected breakdowns, short-term rescheduling could be investigated. In conclusion, future research will have to improve the handling of uncertainty, the coordination of decisions as regards the different actors of the power systems as well as to answer the new challenge power systems will face especially with renewable energies. 


\section{A Classification of the bibliographical references}

Table.2 classifies each reference according to :

- the problem it solves : GMS, TMS (a checkmark in both GMS and TMS columns means that the two problems are addressed in the paper), GMS with network constraints (GMS+N)

- the power system it targets : regulated $(\mathrm{Rg})$ or/and deregulated (Dg)

- the objective function it handles : reliability-based $(\mathrm{R})$, cost-based $(\mathrm{C})$, profits-based $(\mathrm{P})$.

- some features it deals with : forced outage rate (FOR), stochastic demand (D), refueling management $(\mathrm{F})$.

- the solution method it proposes.

It is not however exhaustive to cover the wide range of features that can occur for the maintenance scheduling in electricity industry. Some classifications may also be debated since some studies do not fit well into the boxes, but we aim at being the most consistent. 


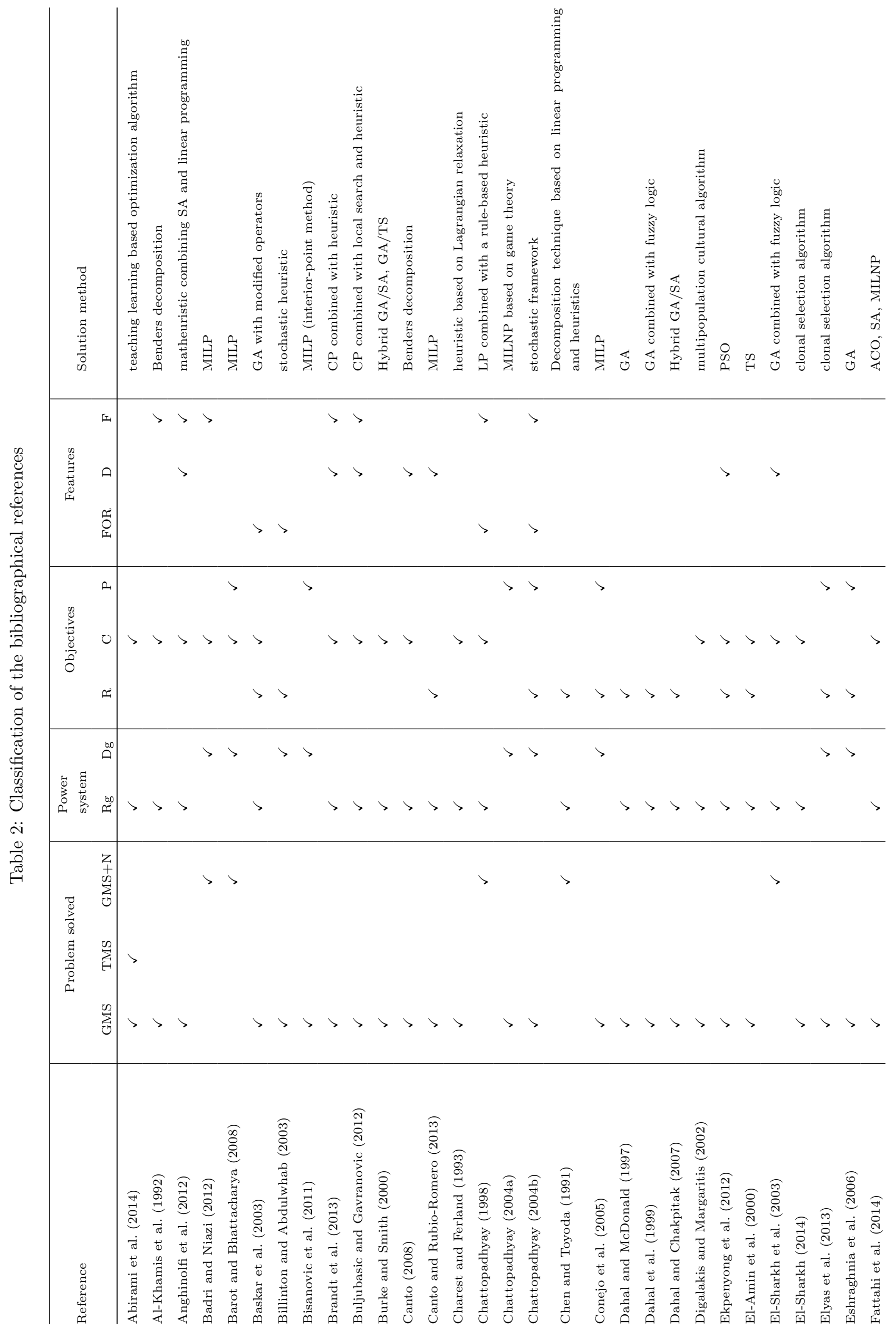




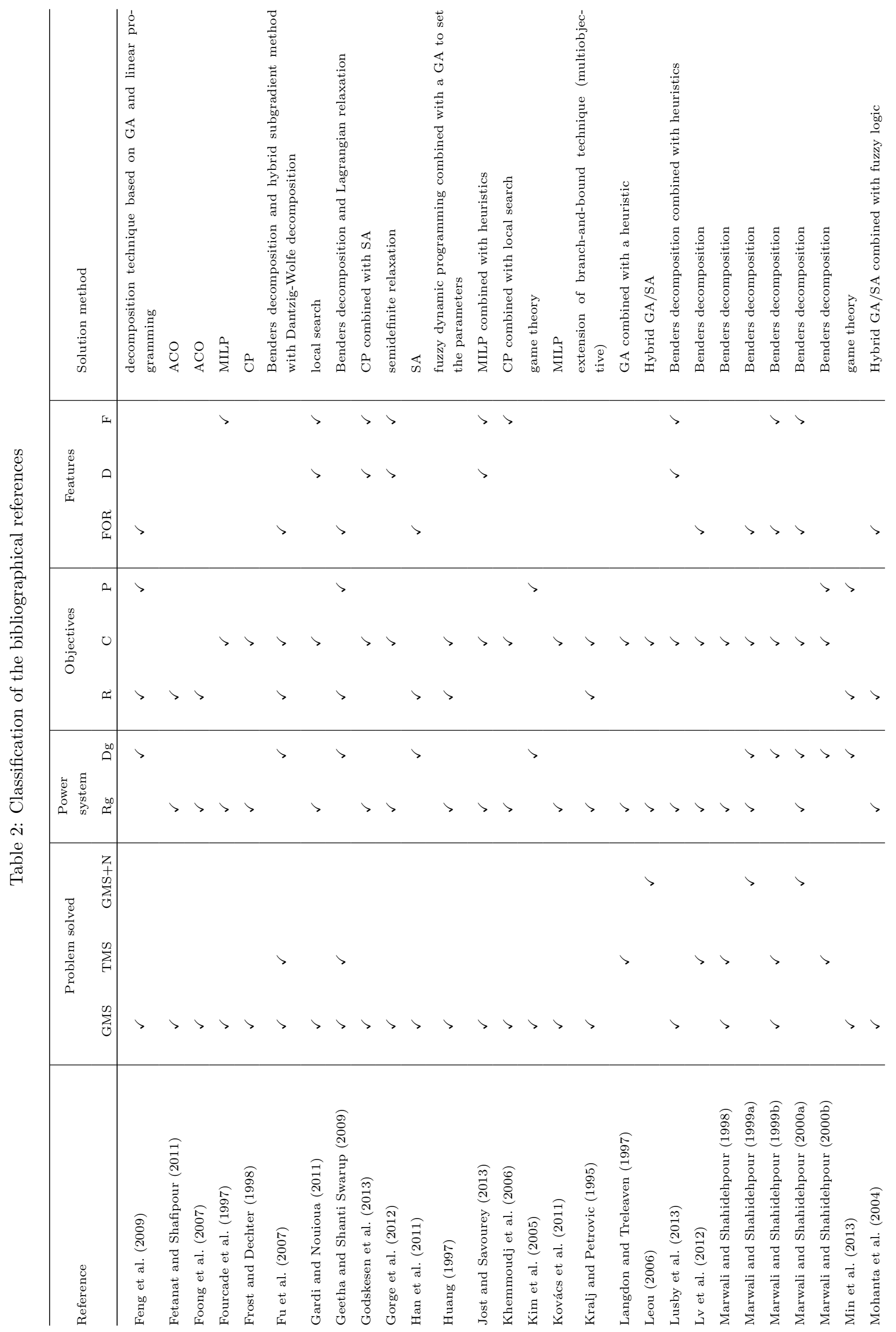




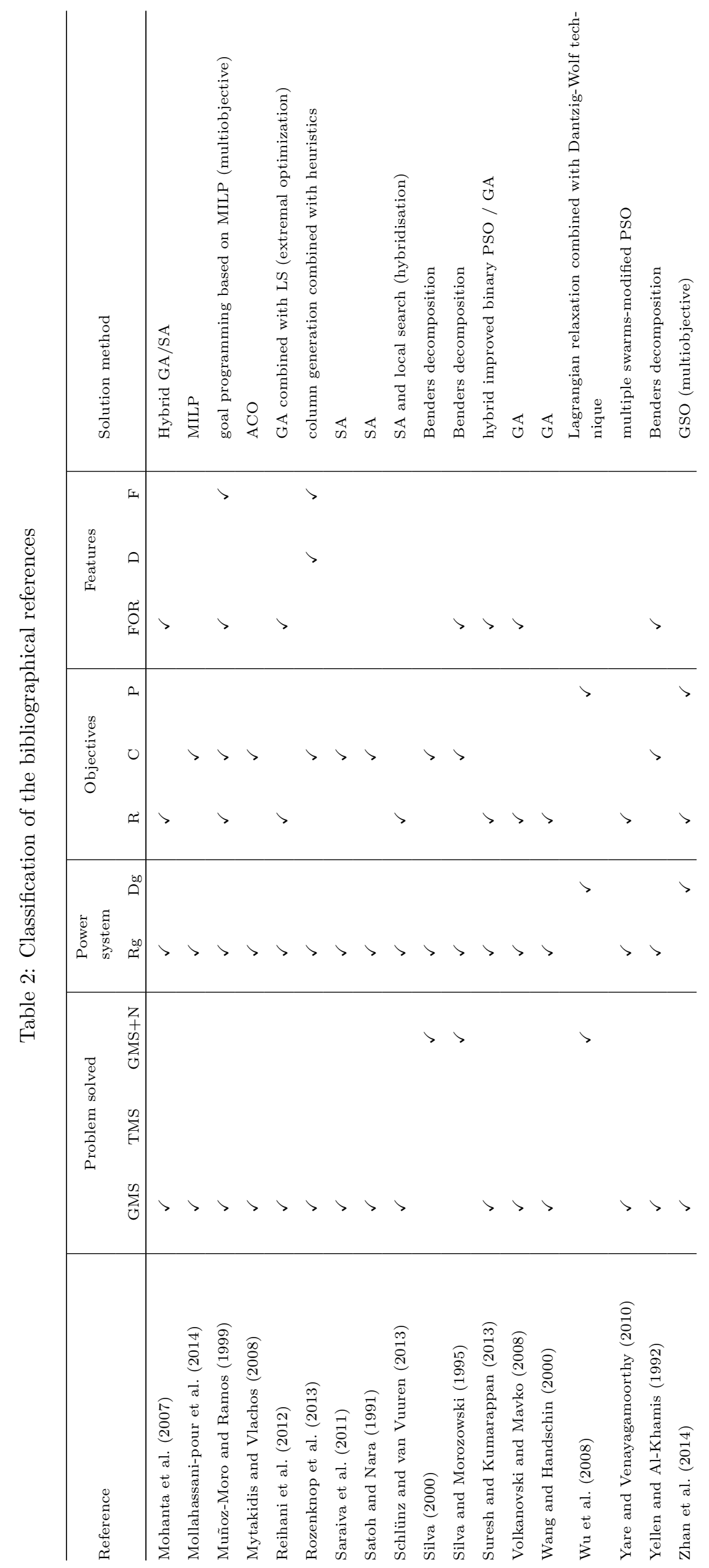




\section{References}

Abirami, M., Ganesan, S., Subramanian, S., and Anandhakumar, R. (2014). Source and transmission line maintenance outage scheduling in a power system using teaching learning based optimization algorithm. Applied Soft Computing, $21: 72-83$.

Al-Khamis, T., Vemuri, S., Lemonidis, L., and Yellen, J. (1992). Unit maintenance scheduling with fuel constraints. IEEE Transactions on Power Systems, 7(2):933-939.

Anghinolfi, D., Gambardella, L., and Montemanni, R. (2012). A matheuristic algorithm for a large-scale energy management problem. In Van Lirkov, I., Margenov, S., and Waśniewsk, J., editors, Large-Scale Scientific Computing, volume 7116, pages 173-181. Springer Berlin Heidelberg.

Badri, A. and Niazi, A. (2012). Preventive generation maintenance scheduling considering system reliability and energy purchase in restructured power systems. Journal of Basic and Applied Scientific Research, 2(12):12773-12786.

Barot, H. and Bhattacharya, K. (2008). Security coordinated maintenance scheduling in deregulation based on genco contribution to unserved energy. IEEE Transactions on Power Systems, 23(4):1871-1882.

Baskar, S., Subbaraj, P., Rao, M., and Tamilselvi, S. (2003). Genetic algorithms solution to generator maintenance scheduling with modified genetic operators. Generation, Transmission and Distribution, IEE Proceedings, 150(1):5660 .

Benders, J. (1962). Partitioning procedures for solving mixed-variables programming problems. Numerische Mathematik, $4(1): 238-252$.

Billinton, R. and Abdulwhab, A. (2003). Short-term generating unit maintenance scheduling in a deregulated power system using a probabilistic approach. Generation, Transmission and Distribution, IEE Proceedings, 150(4).

Bisanovic, S., Hajro, M., and Dlakic, M. (2011). A profit-based maintenance scheduling of thermal power units in electricity market. International Journal of Electrical and Electronics Engineering, 5:156-164.

Brandt, F., Bauer, R., Völker, M., and Cardeneo, A. (2013). A constraint programming-based approach to a large-scale energy management problem with varied constraints. Journal of Scheduling, 16(6):629-648.

Buljubasic, M. and Gavranovic, H. (2012). Orchestrating constrained programming and local search to solve a large scale energy management problem. In Proceedings of the Federated Conference on Computer Science and Information Systems, pages $371-378$.

Burke, E. and Smith, A. (2000). Hybrid evolutionary techniques for the maintenance scheduling problem. IEEE Transactions on Power Systems, 15(1).

Canto, S. (2008). Application of Benders' decomposition to power plant preventive maintenance scheduling. European Journal of Operational Research, 184:759-777.

Canto, S. and Rubio-Romero, J. (2013). A model for the preventive maintenance scheduling of power plants including wind farms. Reliability Engineering 83 System Safety, 119:67-75.

Charest, M. and Ferland, J. (1993). Preventive maintenance scheduling of power generating units. Annals of Operations Research, 41:185-206.

Chattopadhyay, D. (1998). A practical maintenance scheduling program mathematical model and case study. IEEE Transactions on Power Systems, 13(4):1475-1480.

Chattopadhyay, D. (2004a). A game theoretic model for strategic maintenance and dispatch decisions. IEEE Transactions on Power Systems, 19(4):2014-2021.

Chattopadhyay, D. (2004b). Life-cycle maintenance management of generating units in a competitive environment. IEEE Transactions on Power Systems, 19(2):1181-1189. 
Chen, L. and Toyoda, J. (1991). Optimal generating unit maintenance scheduling for multi-area system with network constraints. IEEE Transactions on Power Systems, 6(3):1168-1174.

Conejo, A., Garcia-Bertrand, R., and Diaz-Salazar, M. (2005). Generation maintenance scheduling in restructured power systems. IEEE Transactions on Power Systems, 20(2):984-992.

Dahal, K. (2004). A review of maintenance scheduling approaches in deregulated power systems. In Proceedings of the International Conference on Power Systems (ICPS 2004), Kathmandu, Nepal, pages 565-570.

Dahal, K., Al-Arfaj, K., and Paudyal, K. (2015). Modelling generator maintenance scheduling costs in deregulated power markets. European Journal of Operational Research, 240(2):551-561.

Dahal, K., Aldridge, C., and McDonald, J. (1999). Generator maintenance scheduling using a genetic algorithm with a fuzzy evaluation function. Fuzzy Sets and Systems, 102(1):21-29.

Dahal, K. and Chakpitak, N. (2007). Generator maintenance scheduling in power systems using metaheuristic-based hybrid approaches. Electric Power Systems Research, 77(7):771-779.

Dahal, K. and McDonald, J. (1997). Generator maintenance scheduling of electric power systems using genetic algorithms with integer representations. In Second International Conference On Genetic Algorithms in Engineering Systems: Innovations and Applications, GALESIA 1997., number 446, pages 456-461.

Digalakis, J. and Margaritis, K. (2002). A multipopulation cultural algorithm for the electrical generator scheduling problem. Mathematics and Computers in Simulation, 60(3-5):293-301.

Doyle, E. (2004). On the application of stochastic models in nuclear power plant maintenance. European Journal of Operational Research, 154(3):673-690.

Ekpenyong, U., Zhang, J., and Xia, X. (2012). An improved robust model for generator maintenance scheduling. Electric Power Systems Research, 92:29-36.

El-Amin, I., Duffuaa, S., and Abbas, M. (2000). A tabu search algorithm for maintenance scheduling of generating units. Electric Power Systems Research, 54:91-99.

El-Sharkh, M. (2014). Clonal selection algorithm for power generators maintenance scheduling. International Journal of Electrical Power \& Energy Systems, 57:73-78.

El-Sharkh, M., El-Keib, A., and Chen, H. (2003). A fuzzy evolutionary programming-based solution methodology for security-constrained generation maintenance scheduling. Electric Power Systems Research, 67(1):67-72.

Elyas, S., Akbari Foroud, A., and Chitsaz, H. (2013). A novel method for maintenance scheduling of generating units considering the demand side. International Journal of Electrical Power ES Energy Systems, 51:201-212.

Eshraghnia, R., Modir Shanechi, M., and Rajabi Mashhadi, H. (2006). A new approach for maintenance scheduling of generating units in power market. In International Conference on Probabilistic Methods Applied to Power Systems, pages $9-15$.

Fattahi, M., Mahootchi, M., Mosadegh, H., and Fallahi, F. (2014). A new approach for maintenance scheduling of generating units in electrical power systems based on their operational hours. Computers 83 Operations Research.

Feng, C., Wang, X., and Li, F. (2009). Optimal maintenance scheduling of power producers considering unexpected unit failure. IET Generation, Transmission \& Distribution, 3(5):460-471.

Fetanat, A. and Shafipour, G. (2011). Generation maintenance scheduling in power systems using ant colony optimization for continuous domains based 01 integer programming. Expert Systems with Applications, 38(8):9729-9735.

Foong, W., Simpson, A., Maier, H., and Stolp, S. (2007). Ant colony optimization for power plant maintenance scheduling optimizationa five-station hydropower system. Annals of Operations Research, 159(1):433-450. 
Fourcade, F., Johnson, E., Bara, M., and Cortey-Dumont, P. (1997). Optimizing nuclear power plant refueling with mixed-integer programming. European Journal of Operational Research, 97(2):269-280.

Frost, D. and Dechter, R. (1998). Optimizing with constraints: A case study in scheduling maintenance of electric power units. In Lecture Notes in Computer Science Volume 1520, pages 469-488.

Fu, Y., Shahidehpour, M., and Li, Z. (2007). Security-constrained optimal coordination of generation and transmission maintenance outage scheduling. IEEE Transactions on Power Systems, 22(3):1302-1313.

Gardi, F. and Nouioua, K. (2011). Local search for mixed-integer nonlinear optimization: A methodology and an application. In EvoCop: 11th European conference on evolutionary computation in combinatorial optimisation, 27-29 April 2011 Torino, Italy, pages 167-178.

Geetha, T. and Shanti Swarup, K. (2009). Coordinated preventive maintenance scheduling of GENCO and TRANSCO in restructured power systems. International Journal of Electrical Power E Energy Systems, 31(10):626-638.

Godskesen, S., Jensen, T., Kjeldsen, N., and Larsen, R. (2013). Solving a real-life, large-scale energy management problem. Journal of Scheduling, 16(6):567-583.

Gorge, A., Lisser, A., and Zorgati, R. (2012). Stochastic nuclear outages semidefinite relaxations. Computational Management Science, 9(3):363-379.

Han, S.-M., Chung, K.-H., and Kim, B. (2011). ISO coordination of generator maintenance scheduling in competitive electricity markets using simulated annealing. Journal of Electrical Engineering \& Technology, 6(4):431-438.

Huang, S.-J. (1997). Generator maintenance scheduling: A fuzzy system approach with genetic enhancement. Electric Power Systems Research, 41(3):233-239.

Jost, V. and Savourey, D. (2013). A 01 integer linear programming approach to schedule outages of nuclear power plants. Journal of Scheduling, 16(6):551-566.

Khalid, A. and Ioannis, K. (2012). A survey of generator maintenance scheduling techniques. Global Journal of Researches in Engineering, 12(1).

Khemmoudj, M., Porcheron, M., and Bennaceur, H. (2006). When constraint programming and local search solve the scheduling problem of Electricit de France nuclear power plant outages. In Benhamou, F., editor, Principles and Practice of Constraint Programming - CP 2006, volume 4204 of Lecture Notes in Computer Science, pages 271-283. Springer Berlin Heidelberg.

Kim, J.-H., Park, J.-B., Park, J.-K., and Chun, Y.-H. (2005). Generating unit maintenance scheduling under competitive market environments. International Journal of Electrical Power E Energy Systems, 27(3):189-194.

Kovács, A., Erds, G., Viharos, Z., and Monostori, L. (2011). A system for the detailed scheduling of wind farm maintenance. CIRP Annals - Manufacturing Technology, 60(1):497-501.

Kralj, B. and Petrović, R. (1988). Optimal preventive maintenance scheduling of thermal generating units in power systems - A survey of problem formulations and solution methods. European Journal of Operational Research, 35:1-15.

Kralj, B. and Petrovic, R. (1995). A multiobjective optimization approach to thermal generating units maintenance scheduling. European Journal of Operational Research, 84(2):481-493.

Langdon, W. and Treleaven, P. (1997). Scheduling maintenance of electrical power transmission networks using genetic programming. In Warwick, K., Ekwue, A., and Aggarwal, R., editors, Artificial Intelligence Techniques in Power Systems, chapter 10, pages 220-237. IEE.

Leou, R.-C. (2006). A new method for unit maintenance scheduling considering reliability and operation expense. International Journal of Electrical Power 8 Energy Systems, 28(7):471-481. 
Lusby, R., Muller, L., and Petersen, B. (2013). A solution approach based on Benders decomposition for the preventive maintenance scheduling problem of a stochastic large-scale energy system. Journal of Scheduling, 16(6):605-628.

Lv, C., Wang, J., and Sun, P. (2012). Short-term transmission maintenance scheduling based on the Benders decomposition. In Power and Energy Engineering Conference (APPEEC), 2012 Asia-Pacific, pages 1-5.

Marwali, M. and Shahidehpour, S. (1998). A deterministic approach to generation and transmission maintenance scheduling with network constraints. Electric Power Systems Research, 47(2):101-113.

Marwali, M. and Shahidehpour, S. (1999a). A probabilistic approach to generation maintenance scheduler with network constraints. International Journal of Electrical Power 85 Energy Systems, 21(8):533-545.

Marwali, M. and Shahidehpour, S. (1999b). Long-term transmission and generation maintenance scheduling with network, fuel and emission constraints. IEEE Transactions on Power Systems, 14(3):1160-1165.

Marwali, M. and Shahidehpour, S. (2000a). Coordination between long-term and short-term generation scheduling with network constraints. IEEE Transactions on Power Systems, 15(3):1161-1167.

Marwali, M. and Shahidehpour, S. (2000b). Short-term transmission line maintenance scheduling in a deregulated system. IEEE Transactions on Power Systems, 15(3):1117-1124.

Min, C., Kim, M., Park, J., and Yoon, Y. (2013). Game-theory-based generation maintenance scheduling in electricity markets. Energy, 55:310-318.

Mohanta, D., Sadhu, P., and Chakrabarti, R. (2004). Fuzzy reliability evaluation of captive power plant maintenance scheduling incorporating uncertain forced outage rate and load representation. Electric Power Systems Research, $72(1): 73-84$.

Mohanta, D., Sadhu, P., and Chakrabarti, R. (2007). Deterministic and stochastic approach for safety and reliability optimization of captive power plant maintenance scheduling using GA/SA-based hybrid techniques: A comparison of results. Reliability Engineering \& System Safety, 92(2):187-199.

Mollahassani-pour, M., Abdollahi, A., and Rashidinejad, M. (2014). Application of a novel cost reduction index to preventive maintenance scheduling. International Journal of Electrical Power E Energy Systems, 56:235-240.

Muñoz-Moro, L. and Ramos, A. (1999). Goal programming approach to maintenance scheduling of generating units in large scale power systems. IEEE Transactions on Power Systems, 14(3):1021-1028.

Mytakidis, T. and Vlachos, A. (2008). Maintenance scheduling by using the bi-criterion algorithm of preferential antipheromones. Leonardo Journal of Sciences, (12):143-164.

Porcheron, M., Gorge, A., Juan, O., Simovic, T., and Dereu, G. (2010). Challenge ROADEF/EURO 2010: A large-scale energy management problem with varied constraints.

Reihani, E., Sarikhani, A., and Davodi, M. (2012). Reliability based generator maintenance scheduling using hybrid evolutionary approach. International Journal of Electrical Power E Energy Systems, 42(1):434-439.

Reliability Test System Task Force of the Application of Probability Methods Subcommittee (1979). IEEE reliability test system. IEEE Transactions on Power Apparatus and Systems, PAS-98(6):2047-2054.

Reliability Test System Task Force of the Application of Probability Methods Subcommittee (1999). The IEEE reliability test system - 1996. IEEE Transactions on Power Systems, 14(3):1010-1020.

Rozenknop, A., Wolfler Calvo, R., Alfandari, L., Chemla, D., and Létocart, L. (2013). Solving the electricity production planning problem by a column generation based heuristic. Journal of Scheduling, 16(6):585-604.

Saraiva, J., Pereira, M., Mendes, V., and Sousa, J. (2011). A simulated annealing based approach to solve the generator maintenance scheduling problem. Electric Power Systems Research, 81(7):1283-1291. 
Satoh, T. and Nara, K. (1991). Maintenance scheduling by using simulated annealing method. IEEE Transactions on Power Systems, 6(2):850-857.

Schlünz, E. and van Vuuren, J. (2013). An investigation into the effectiveness of simulated annealing as a solution approach for the generator maintenance scheduling problem. International Journal of Electrical Power 8 Energy Systems, 53:166-174.

Shahidehpour, M., Yamin, H., and Li, Z. (2002). Market Operations in Electric Power Systems. Wiley-IEEE Press.

Silva, E. (2000). Generation maintenance scheduling considering transmission constraints. IEEE Transactions on Power Systems, 15(2):838-843.

Silva, E. and Morozowski, M. (1995). Transmission constrained maintenance scheduling of generating units: A stochastic programming approach. IEEE Transactions on Power Systems, 10(2):695-701.

Suresh, K. and Kumarappan, N. (2013). Hybrid improved binary particle swarm optimization approach for generation maintenance scheduling problem. Swarm and Evolutionary Computation, 9:69-89.

Volkanovski, A. and Mavko, B. (2008). Genetic algorithm optimisation of the maintenance scheduling of generating units in a power system. Reliability Engineering \& System Safety, 93(6):757-767.

Wang, Y. and Handschin, E. (2000). A new genetic algorithm for preventive unit maintenance scheduling of power systems. Journal of Electrical Power \& Energy Systems, 22(5):343-348.

Wu, L., Shahidehpour, M., and Li, T. (2008). GENCO's risk-based maintenance outage scheduling. IEEE Transactions on Power Systems, 23(1):127-136.

Yamayee, Z. (1982). Maintenance scheduling: Description, literature survey, and interface with overall operations scheduling. IEEE Transactions on Power Apparatus and Systems, 75(8):2770-2779.

Yamayee, Z., Sidenblad, K., and Yoshimura, M. (1983). A computationally efficient optimal maintenance scheduling method. IEEE Transactions on Power Apparatus and Systems, PAS-102(2):330-338.

Yare, Y. and Venayagamoorthy, G. (2010). Optimal maintenance scheduling of generators using multiple swarmsMDPSO framework. Engineering Applications of Artificial Intelligence, 23(6):895-910.

Yellen, J. and Al-Khamis, T. (1992). A decomposition approach to unit maintenance scheduling. IEEE Transactions on Power Systems, 7(2):726-733.

Yssaad, B., Khiat, M., and Chaker, A. (2014). Reliability centered maintenance optimization for power distribution systems. International Journal of Electrical Power \& Energy Systems, 55:108-115.

Zhan, J., Guo, C., Wu, Q., and Zhang, L. (2014). Generation Maintenance Scheduling Based on Multiple Objectives and Their Relationship Analysis. Journal of Zhejiang University, pages 1-13. 